\title{
What does matter for AUS/FLUS: size, sex or age?
}

Ana Alves Rafael', Sílvia Sofia Silva', Ricardo Rodrigues Marques, João Sequeira Duarte², Luis Viana Fernades

${ }^{1} \mathrm{CHLO}$, EPE - Hospital Egas Moniz - Department Cirurgia II, Lisboa, Portugal ${ }^{2}$ CHLO, EPE - Hospital Egas Moniz - Department Endocrinologia, Lisboa, Portugal

\section{BACKGROUND}

The clinical attitude to the treatment of Bethesda System Category III lesions has been under controversy. Our aim was to analyse three variables and to establish a possible predictive value for carcinoma in patients with AUS/FLUS nodules.

\section{METHODS}

Retrospective study of 671 thyroid fine-needle aspirations (FNAs) classified as AUS/FLUS between January 2012 and June 2015. Size, sex and age were analysed using SPSS.

\section{RESULTS}

$671(14.8 \%)$ FNAs were initially classified as Bethesda's category III, in a database of 4549 FNAs from 3696 patients.

195 patients underwent surgery. The risk of malignancy for operated patients was $29.7 \%$.

January 2012 - June 2015

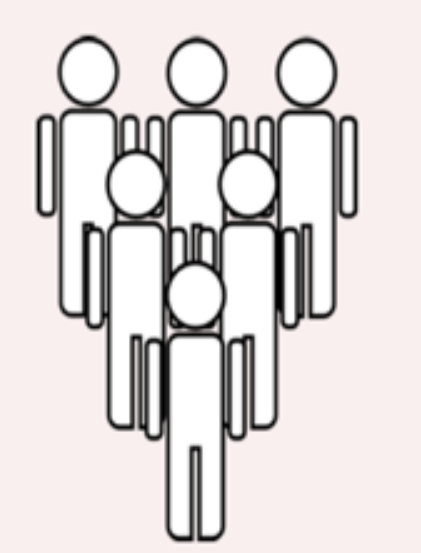

$$
\mathrm{N}=3696 \text { patients }
$$

4549 thyroid FNAs

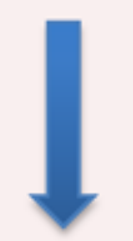

671 AUS/FLUS (14.8\%)

$\mathrm{N}=195$ patients operated

Carcinomas: 58

(29.7\%)

Benign: 137

$(70,3 \%)$

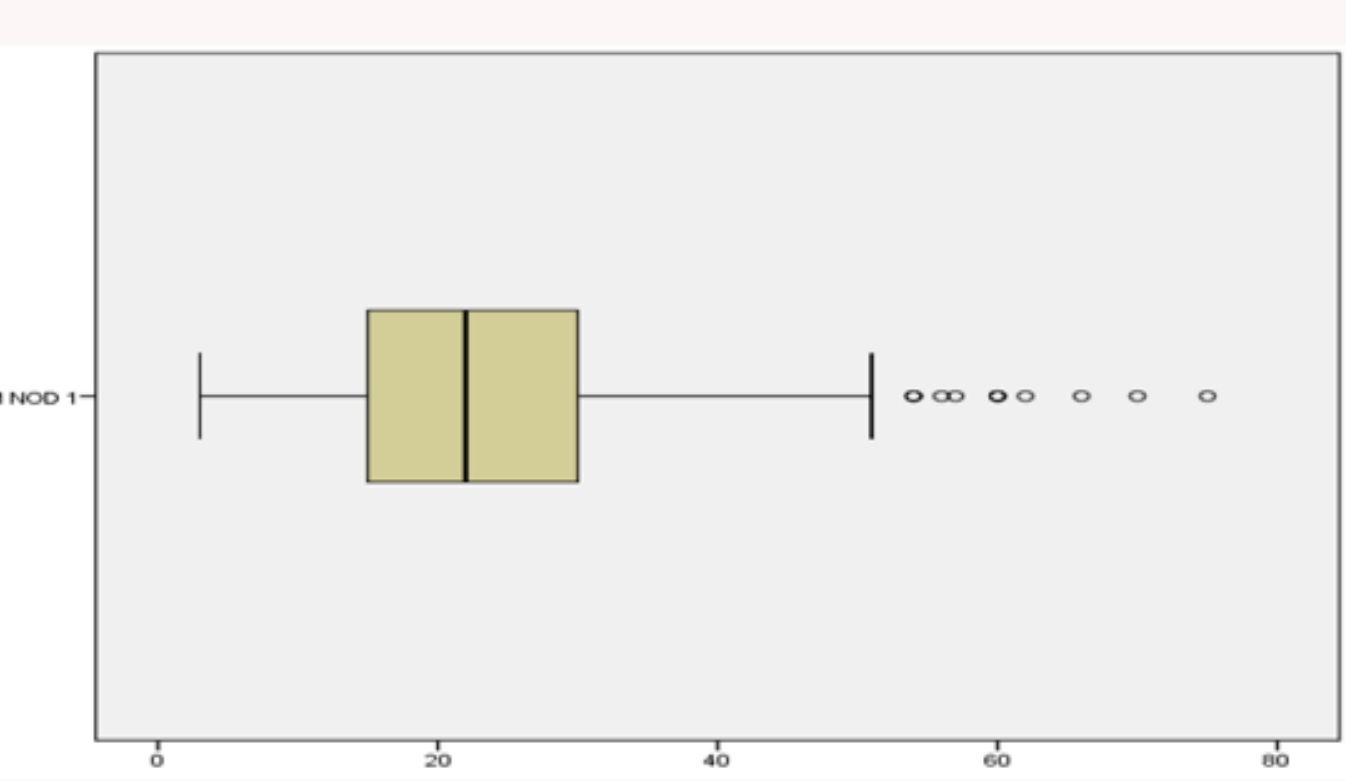

Nodule mean size was $24.4 \mathrm{~mm}$

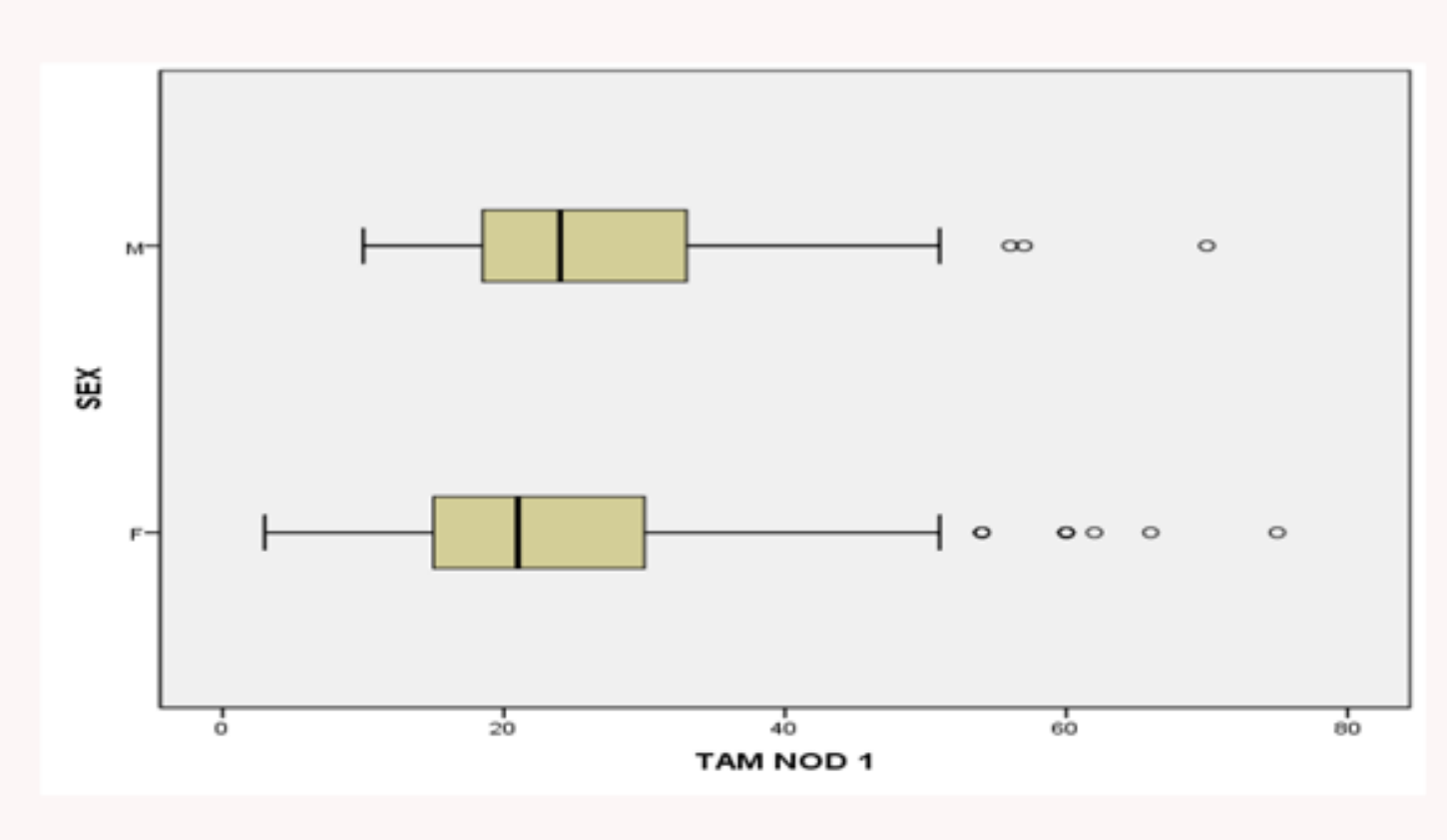

Nodules were bigger in men than in women $(27 \mathrm{~mm} / 24 \mathrm{~mm})$
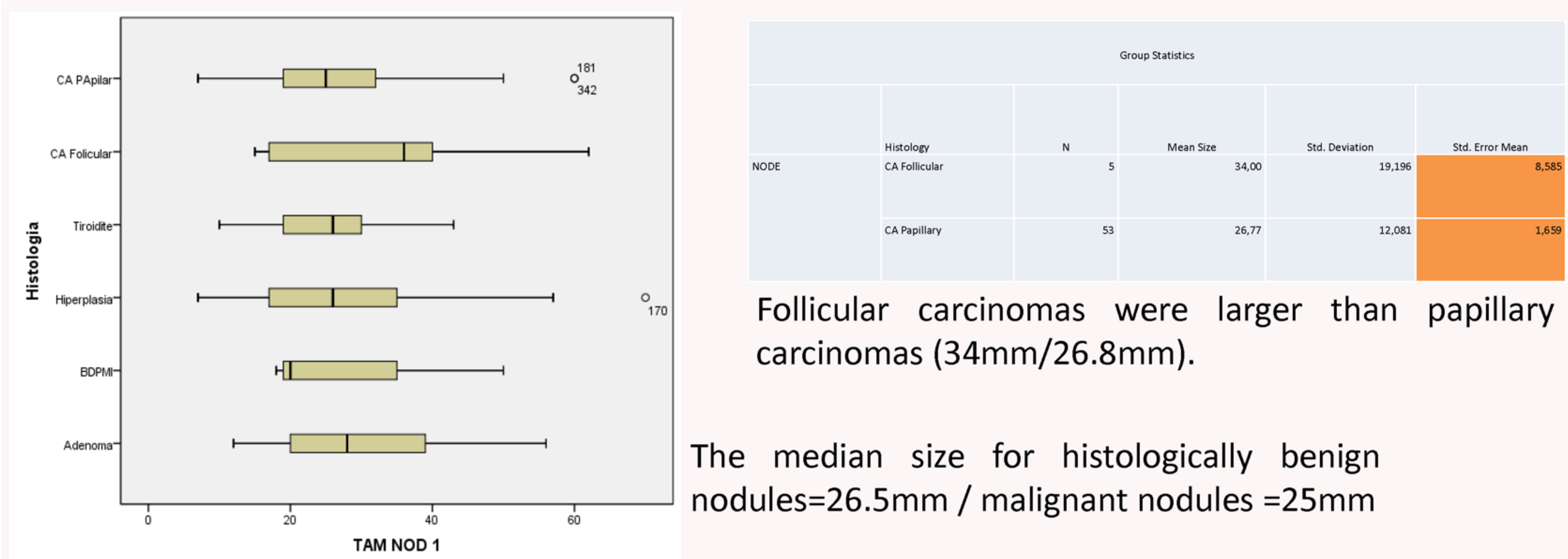

Follicular carcinomas were larger than papillary carcinomas $(34 \mathrm{~mm} / 26.8 \mathrm{~mm})$.

The median size for histologically benign nodules $=26.5 \mathrm{~mm} /$ malignant nodules $=25 \mathrm{~mm}$
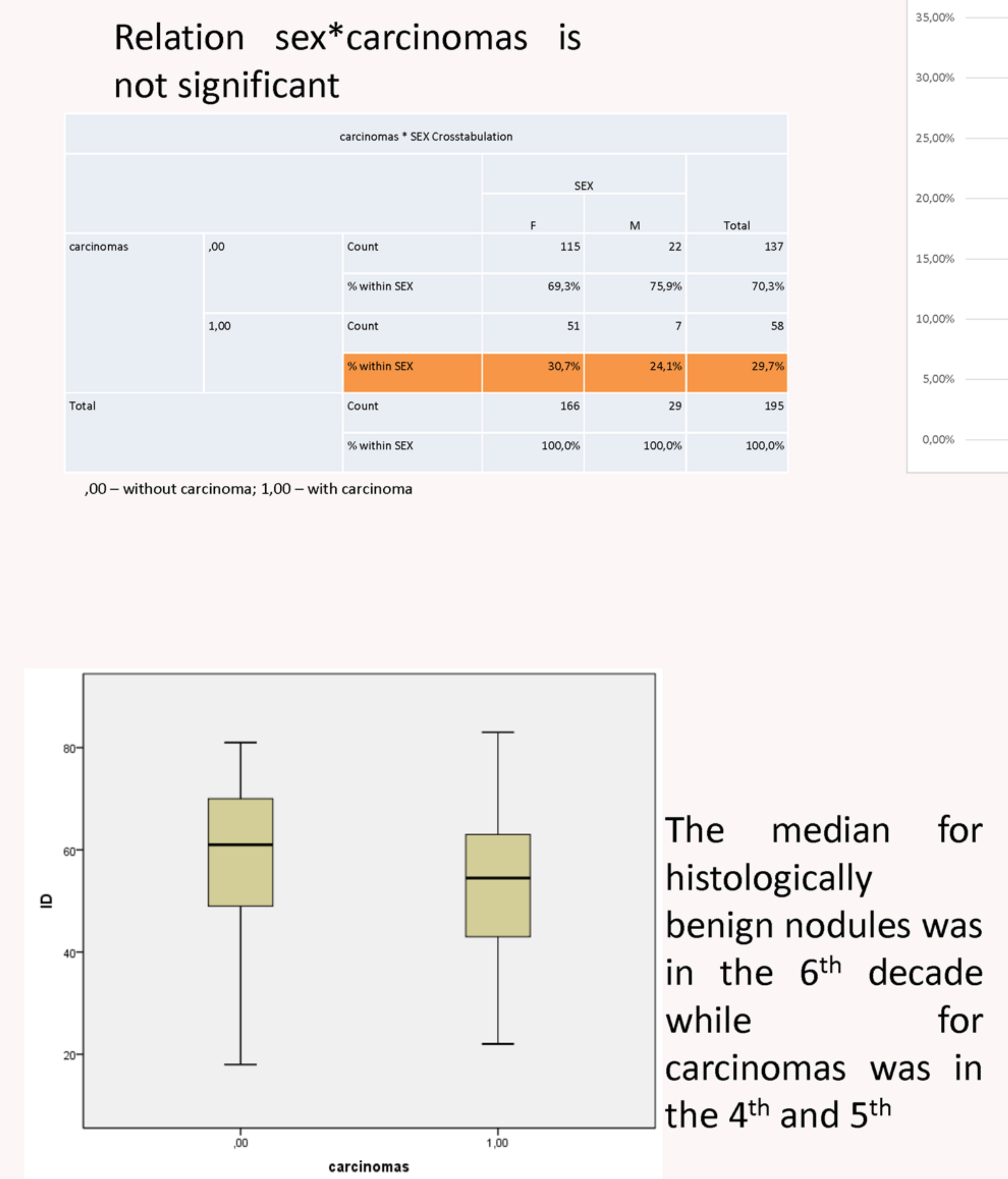

The probability of carcinoma reduces $23,7 \%$ per decade according to a multifactorial analysis

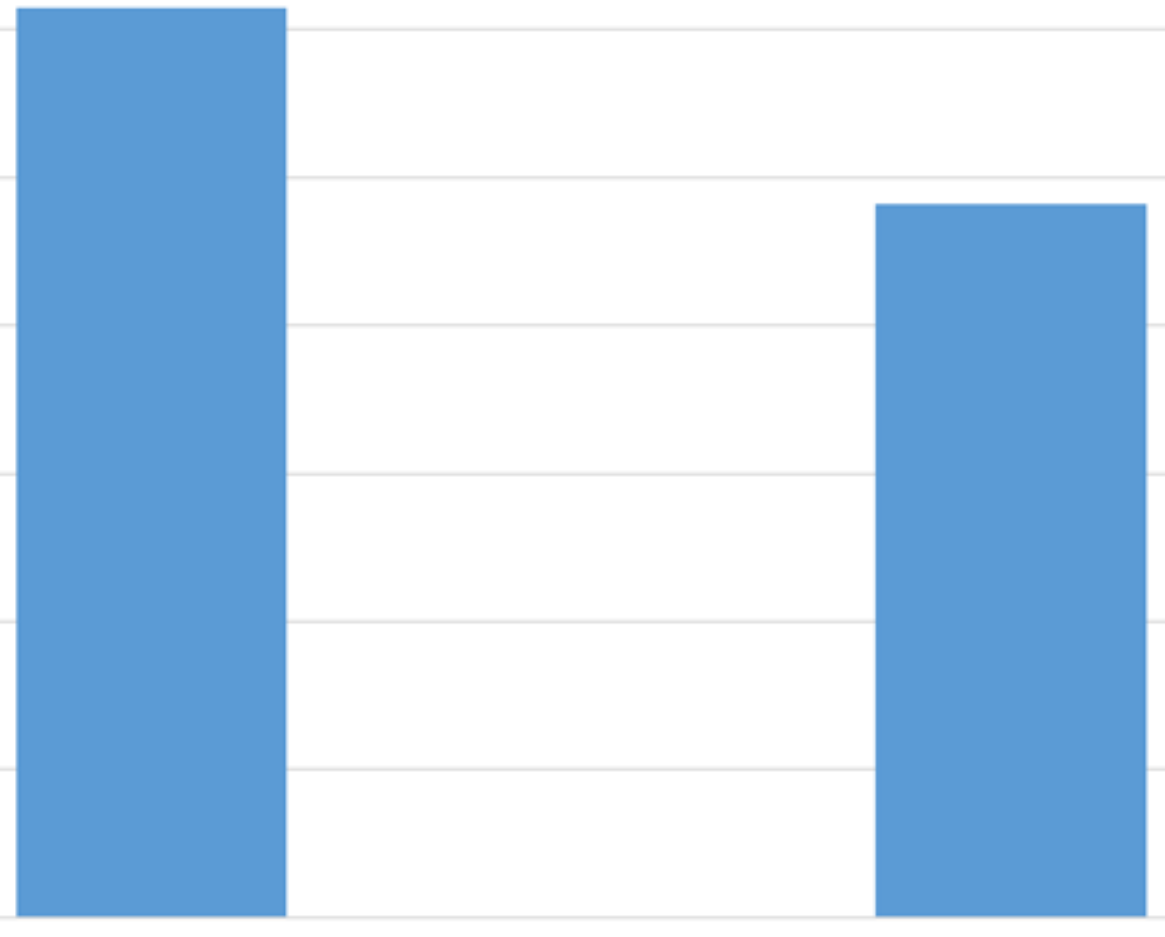

\section{DISCUSSION / CONCLUSION}

Age was the only variable with predictable value for carcinoma in AUS/FLUS

The probability of carcinoma reduces $2,3 \%$ per year and $23,7 \%$ per decade according to a multifactorial analysis.

Patients over 70s have 5 times less probability of carcinoma than those under 40 s.

According to that, the authors suggest that surveillance may be enough for patients over 70 s with AUS/FLUS nodules.

\section{BIBLIOGRAPHY}

1) 2015 American Thyroid Association Management Guidelines for Adult Patients wih Thyroid Nodules and Differentiated Thyroid Cancer: 1

凶: Serviço Cirurgia II, Hospital Egas Moniz Rua Da Junqueira 126, 1349-019 Lisboa @: anarafael2002@gmail.com 